\title{
Mepivacaine reduces calcium transients in isolated murine ventricular cardiomyocytes
}

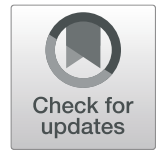

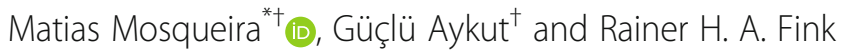

\begin{abstract}
Background: The potential mechanism of mepivacaine's myocardial depressant effect observed in papillary muscle has not yet been investigated at cellular level. Therefore, we evaluated mepivacaine's effects on $\mathrm{Ca}^{2+}$ transient in isolated adult mouse cardiomyocytes.

Methods: Single ventricular myocytes were enzymatically isolated from wild-type C57BI/6 mice and loaded with $10 \mu \mathrm{M}$ fluorescent $\mathrm{Ca}^{2+}$ indicator Fluo-4-AM to record intracellular $\mathrm{Ca}^{2+}$ transients upon electrical stimulation. The mepivacaine effects at half-maximal inhibitory concentration $\left(I C_{50}\right)$ was determined on calibrated cardiomyocytes' $\mathrm{Ca}^{2+}$ transients by non-parametric statistical analyses on biophysical parameters. Combination of mepivacaine with $\mathrm{NCX}$ blockers ORM-10103 or $\mathrm{NiCl}_{2}$ were used to test a possible mechanism to explain mepivacaine-induced $\mathrm{Ca}^{2+}$ transients' reduction.

Results: A significant inhibition at mepivacaine's $\mathrm{IC}_{50}(50 \mu \mathrm{M})$ on $\mathrm{Ca}^{2+}$ transients was measured in biophysical parameters such as peak (control: $528.6 \pm 73.61 \mathrm{nM}$ vs mepivacaine: $130.9 \pm 15.63 \mathrm{nM}$; $p<0.05$ ), peak area (control: $401.7 \pm 63.09 \mathrm{nM}^{*} \mathrm{~s}$ vs mepivacaine: $72.14 \pm 10.46 \mathrm{nM}^{*} \mathrm{~s} ; p<0.05$ ), slope (control: $7699 \pm 1110 \mathrm{nM} / \mathrm{s}$ vs mepivacaine: $1686 \pm 226.6 \mathrm{nM} / \mathrm{s} ; p<0.05$ ), time to peak (control: $107.9 \pm 8.967 \mathrm{~ms}$ vs mepivacaine: $83.61 \pm 7.650 \mathrm{~ms} ; \mathrm{p}<0.05)$ and $\mathrm{D}_{50}$ (control: $457.1 \pm 47.16 \mathrm{~ms}$ vs mepivacaine: $284.5 \pm 22.71 \mathrm{~ms} ; \mathrm{p}<0.05$ ). Combination of mepivacaine with NCX blockers ORM-10103 or $\mathrm{NiCl}_{2}$ showed a significant increase in the baseline of $\left[\mathrm{Ca}^{2+}\right]$ and arrhythmic activity upon electrical stimulation.
\end{abstract}

Conclusion: At cellular level, mepivacaine blocks $\mathrm{Na}^{+}$channels, enhancing the reverse mode activity of NCX, leading to a significant reduction of $\mathrm{Ca}^{2+}$ transients. These results suggest a new mechanism for the mepivacainereduction contractility effect.

Keywords: Local anesthetic, Mepivacaine, $\mathrm{Ca}^{2+}$ transients, Mouse, Cardiomyocytes

\section{Background}

Hemodynamic changes caused by local anesthetics may be of major clinical concern. Among others, these hemodynamic effects associated with local anesthetics include a decrease in ventricular conduction velocity leading to arrhythmias and a decrease in myocardial contractility [1-3]. Mepivacaine is a widely used amidetype local anesthetic, which demonstrates a rapid metabolism via the liver and a rapid excretion via the kidneys. Clinically, mepivacaine shows a short onset time, intermediate duration and low toxicity, which can therefore

\footnotetext{
* Correspondence: matias@physiologie.uni-heidelberg.de

${ }^{+}$Matias Mosqueira and Güçlü Aykut contributed equally to this work. Cardio-Ventilatory Muscle Physiology Laboratory, Institute of Physiology and Pathophysiology, Heidelberg University Hospital, Im Neuenheimer Feld 326, 69120 Heidelberg, Germany
}

be regarded as a safe drug in high risk cardiac patients [4]. However, it has been shown that mepivacaine induces shortening of the QRS complexes, decreases of QTc-interval and ventricular arrhythmias $[5,6]$. In dogs, mepivacaine induces decrease of the heart rate, cardiac output and stroke volume, increasing the area-undercurve of T-wave, lengthening QTU interval. These cardiac alterations can be explained as $40 \mu \mathrm{M}$ mepivacaineinduced reduction in the $\mathrm{Na}^{+}$current's $\left(\mathrm{I}_{\mathrm{Na}}\right)$ measured parameters such as overshoot, $\mathrm{dv} / \mathrm{dt}_{\max }$ and action potential at $20 \%$ of repolarization $\left(\mathrm{APD}_{20}\right)$ [7]. As consequence of $\mathrm{I}_{\mathrm{Na}}$ reduction, myocardial depression in ventricular papillary muscles caused by mepivacaine has also been reported $[8,9]$, without the potential mechanism of mepivacaine's myocardial depressant effect. 
Additionally, to our knowledge there are no conclusive studies about direct effects of mepivacaine at cellular level, which would clarify the mechanism of mepivacaine's effect on intrinsic myocardial contractility. Therefore, we hypothesized that known mepivacaine's effect on $\mathrm{I}_{\mathrm{Na}}$ might cause a reduction of $\mathrm{Ca}^{2+}$ transient at the $\mathrm{IC}_{50}$ for isolated murine cardiomyocyte, explaining the negative inotropic effect of mepivacaine previously described. To test this hypothesis we analyzed $\mathrm{Ca}^{2+}$ transients' biophysical parameters established in our laboratory [10-12]. We observed in isolated adult mouse ventricular cardiomyocytes that mepivacaine's effect at the $\mathrm{IC}_{50}$ calculated from the dose-response analysis, which is considered supra-clinical in humans, significantly reduced $\mathrm{Ca}^{2+}$ release from the sarcoplasmic reticulum. One suggested mechanism to explain this reduction on $\mathrm{Ca}^{2+}$ transient is the NCX reverse mode activity, that would reduce $\left[\mathrm{Ca}^{2+}\right]_{\mathrm{i}}$ in order to keep the $\left[\mathrm{Na}^{+}\right]_{\mathrm{i}}$. The final result supports this hypothesis showing that the combination of mepivacaine and an specific NCX blocker ORM10103 or $\mathrm{NiCl}_{2}$ alters the $\mathrm{Ca}^{2+}$ homeostasis.

\section{Methods}

\section{Ethical statement}

All animal experiments were performed in accordance with the governmental guidelines of the state Baden Württemberg, including the German law on animal experimentation, and were approved by the ethics committee of Heidelberg University Interfaculty Biomedical Research Facility (T84/14) and followed relevant aspects of ARRIVE guidelines. Isolated cardiomyocytes were obtained from five 6-month male $\mathrm{C} 57 \mathrm{BL} / 6 \mathrm{NCrl}$ mice purchased from Charles River, Europe and kept in the Interfaculty Biomedical Research Facility until use under $12 \mathrm{~h}$ light/ dark cycle with food and water ad libitum.

\section{Cardiomyocyte isolation}

Isolation of single cardiac cells was carried out in a modified Langendorff system by the method of Liao and Jain as described previously [13] and adapted by us [12]. Prior to dissection and cannulation of the heart, the perfusion system was filled with perfusion solution and cleared off any air bubbles. Twenty minutes after i.p. heparinization $(8 \mathrm{mg})$ the mouse was killed by cervical dislocation. The heart was excised and quickly perfused using the Langendorff apparatus with a $\mathrm{Ca}^{2+}$ free perfusion solution for $5 \mathrm{~min}$ containing the following (in $\mathrm{mM}$ ): $\mathrm{NaCl}: 135$; KCL: 4; $\mathrm{MgCl}_{2}{ }^{*} 6 \mathrm{H}_{2} \mathrm{O}: 1$; HEPES: 10 ; $\mathrm{NaH}_{2} \mathrm{PO}_{4}$ : 0.33; Glucose: 10; BDM: 20; Taurine: 5 with a $\mathrm{pH}$ value of 7.2 at room temperature. Following the perfusion solution, a $\mathrm{Ca}^{2+}$ free digestion solution was applied which was consisting of Collagenase D $0,36 \mathrm{mg} / \mathrm{g}$ (Roche cat no. 11088858001), Collagenase B 0,48 mg/g (Roche cat no. 11088807001) and protease XIV: 0,06 $\mathrm{mg} / \mathrm{g}$ (Sigma-Aldrich cat no. P5147) dissolved in $30 \mathrm{ml}$ perfusion solution. After $20 \mathrm{~min}$ appropriate digestion, the heart was once more perfused with perfusion solution for $5 \mathrm{~min}$ to wash out the enzymes. The ventricles were then mechanically dissociated in Transfer Buffer-A (TB-A) solution containing (in $\mathrm{mM}$ ): $\mathrm{NaCl}$ : 135 ; KCL: 4; $\mathrm{MgCl}_{2}{ }^{*} 6 \mathrm{H}_{2} \mathrm{O}: 1$; HEPES: 10; $\mathrm{NaH}_{2} \mathrm{PO}_{4}$ : 0.33; Glucose: 5.5; BDM: 15 ; BSA: $5 \mathrm{mg} / \mathrm{ml}$; $\mathrm{pH}: 7.2$ at room temperature. For plating, the cardiomyocytes were placed on $35 \mathrm{~mm}$ petri dishes (Imaging Dish CG cat no 5160-30, ZellKontakt $\mathrm{GmbH}$, Germany) previously coated with extracellular matrix (ECM, cat no. E127, Sigma Aldrich, Germany). Extracellular $\mathrm{Ca}^{2+}$ content was increased in steps (from 0 to 0.6 and then to $1,2 \mathrm{mM}$ ) by mixing TB-A with a phosphate-free HEPES buffered Transfer Buffer-B (TB-B) solution containing the following (in $\mathrm{mM}$ ): $\mathrm{NaCl}$ : 137; KCL: 5.4; $\mathrm{MgCl}_{2}{ }^{*} 6 \mathrm{H}_{2} \mathrm{O}: 1 ; \mathrm{CaCl}_{2} * 2 \mathrm{H}_{2} \mathrm{O}: 1.8$; HEPES: 10; Glucose: 5.5; pH: 7.4 at room temperature. Isolated myocytes were then incubated in TB-B containing $10 \mu \mathrm{M}$ Fluo-4-acetoxymethyl ester (Fluo-4 AM), at $37^{\circ} \mathrm{C}$ for 30 min until introduced into the experimental chamber.

\section{Fluorescence measurements}

As previously described [12], the experimental chamber was mounted on an inverted microscope (Olympus OSP-3 photomultiplier system, Olympus, Tokyo, Japan). After the incubation with Fluo-4 AM, every petri dish was positioned on the experimental chamber and was filled TB-B solution. After an equilibration period with TB-B for $5 \mathrm{~min}$, an appropriate myocyte was chosen for the measurement under the $20 \mathrm{X}$ objective with normal light source according to the following criteria: (a) rodshaped appearance with clear striations and no membrane blebs, (b) a negative staircase of twitch performance on stimulation from rest, and (c) the absence of spontaneous contractions. Cardiomyocytes' $\mathrm{Ca}^{2+}$ transients were examined with a fluorescence light system (Olympus) through a 40X objective (Olympus) using the 488-nm filter for a $75 \mathrm{~W}$ Xenon light source. Fluorescence emission was monitored at $510 \mathrm{~nm}$. During recordings the cells were flanked with two platinum electrodes and field electrically stimulated (single twitch at $0.5 \mathrm{~Hz}, 25 \mathrm{~V}, 10 \mathrm{~ms}$ duration) using SI-Heidelberg Stimulator (Scientific Instruments-Heidelberg, Heidelberg, Germany). The signals were digitally recorded using PowerLab 4/35 (AD Instruments) and analyzed offline after calibration utilizing LabChart 8 software. For each cardiomyocyte ten consecutive stimulations were recorded, but only the last seven $\mathrm{Ca}^{2+}$ transients were averaged and analyzed in order to avoid differences in the sarcoplasmic reticulum's $\mathrm{Ca}^{2+}$ loading due to inactivation between two recordings [14-16]. After control cells were examined in every dish, mepivacaine dissolved in TB-B 
solution as described in experimental protocol was equilibrated for $5 \mathrm{~min}$ before recording $\mathrm{Ca}^{2+}$ transients.

\section{Calibration}

Calibration procedure for converting the voltage signal to $\mathrm{Ca}^{2+}$ concentration was performed at the end of every experiment as previously described [10-12]. Briefly, the background of the petri dish was recorded in 10 different spots (no cells). After incubation with calibration solution I containing (in $\mathrm{mM}$ ): $\mathrm{NaCl}: 140 ; \mathrm{KCl}: 5 ; \mathrm{KH}_{2} \mathrm{PO}_{4}$ : 1.2; $\mathrm{MgCl}_{2} * 6 \mathrm{H}_{2} \mathrm{O}: 1.2 ; \mathrm{CaCl}_{2} * 2 \mathrm{H}_{2} \mathrm{O}$ : 4; HEPES: 20; Ionomycin: 0.005; CPA: 0.01; Caffeine: 5; Ouabain: 1 at room temperature, 10 cardiomyocytes incubated in $10 \mu \mathrm{M}$ Fluo- $4 \mathrm{AM}$ at $37^{\circ} \mathrm{C}$ for $30 \mathrm{~min}$ cells were recorded as maximum fluorescence $\left(F_{\max }\right)$. Then the petri dish was washed twice with TB-B and incubated at room temperature with calibration solution II containing (in $\mathrm{mM}$ ): LiCl: 140 ; $\mathrm{KCl}: 5 ; \mathrm{KH}_{2} \mathrm{PO}_{4}: 1.2 ; \mathrm{MgCl}_{2} * 6 \mathrm{H}_{2} \mathrm{O}: 1.2$; HEPES: 20; EGTA: 4; Ionomycin: 0.005; CPA: 0.01; Caffeine: 5; Ouabain: 1 . At the end 10 cells were recorded as minimum fluorescence $\left(\mathrm{F}_{\min }\right)$. The range of $\mathrm{Ca}^{2+}$ concentration to established $F_{\max }$ and $F_{\min }$ was 0 to $4 \mathrm{mM}$, respectively. Once both $F_{\max }$ and $F_{\min }$ were determined, the background was subtracted and then used to transform voltage into $\mathrm{Ca}^{2+}$ concentration using the following formula: $\left[\mathrm{Ca}^{2+}\right]_{\mathrm{i}}=\mathrm{Kd}\left[\left(\mathrm{F}-\mathrm{F}_{\min }\right) /\left(\mathrm{F}_{\max }-\mathrm{F}\right)\right][17] . \mathrm{Kd}$ is the apparent dissociation constant of the Fluo-4-AM provided by the manufacturer $(345 \mathrm{nM})$ and $\mathrm{F}$ represents the $\mathrm{Ca}^{2+}$ transient signal in volts recorded directly from the photomultiplier. After the conversion from volt signal to $\mathrm{Ca}^{2+}$ concentration, the data were analyzed, as previously described.

\section{Analysis of $\mathrm{Ca}^{2+}$ transients}

To determine the effect of mepivacaine on $\mathrm{Ca}^{2+}$ handling properties of the cells, biophysical parameters were analyzed in Peak Analysis extension from LabChart 8 software as previously mentioned [10-12]: baseline $\left(\mathrm{Ca}^{2+}\right.$ concentration before the electrical stimulation; $\mathrm{nM}$ ), peak area (area under the curve of the fluorescence signal; $\mathrm{nM}^{*} \mathrm{~s}$ ), duration (time from the initial until the end of $\mathrm{Ca}^{2+}$ transient; $\left.\mathrm{ms}\right)$, duration ${ }_{50}\left(\mathrm{D}_{50}\right.$; duration of the transient at $50 \%$ of the maximal peak; ms), peak (increase of the signal from baseline to maximum fluorescence intensity; $\mathrm{nM}$ ), slope (rapidity of increment of the fluorescence from baseline to maximum peak; $\mathrm{nM} / \mathrm{s}$ ), time to peak (time of increment of the fluorescence from baseline to maximum peak; ms), tau (time constant decay between 90 and $5 \%$ of the fluorescence signal), and time to uptake (time of decrement of the fluorescence from maximum peak to baseline; ms). These parameters were divided into three categories: the parameters which describe the general aspects of the $\mathrm{Ca}^{2+}$ transients (peak area, duration and $\mathrm{D}_{50}$ ), the parameters which evaluate the $\mathrm{Ca}^{2+}$ release (peak, time to peak and slope) and the parameters which specify the $\mathrm{Ca}^{2+}$ uptake (tau and time to uptake). All raw data were published in public archive (DOI: https://doi.org/10. 6084/m9.figshare.7713074.v1).

\section{Experimental protocol}

Concentration-response relationship of mepivacaine was investigated in order to calculate the inhibitory effect at $50 \%$ of the response $\left(\mathrm{IC}_{50}\right)$ of mepivacaine for our experiments. Myocytes were exposed to six concentrations of mepivacaine $(10,20,40,50,75$ and $100 \mu \mathrm{M})$. Four 35 $\mathrm{mm}$ dishes were prepared from each heart to test three different concentration. First 5-10 myocytes on every dish were examined as controls with TB-B solution. Then TB-B was removed and the TB-B solution containing each concentration of mepivacaine. After the $\mathrm{IC}_{50}$ was determined, $\mathrm{Ca}^{2+}$ transients from 42 cardiomyocytes were analyzed in control solution. After a 5-min equilibration period with $50-\mu \mathrm{M}$ mepivacaine, $\mathrm{Ca}^{2+}$ transients from 29 cardiomyocytes were recorded. For NCX contribution, 5-10 isolated cardiomyocytes in control solution were recorded from each plate, then 31 different isolated cardiomyocytes incubated with $\mathrm{NiCl}_{2} 1 \mathrm{mM}$ or 24 isolated cardiomyocytes incubated ORM-10103 $10 \mu \mathrm{M}$ and then 10 cardiomyocytes recorded with the combination of $\mathrm{NiCl}_{2}$ and mepivacaine and 10 cardiomyocytes recorded with ORM and mepivacaine.

\section{Materials}

Except where noted above, all reagents were obtained from Sigma Aldrich (Sigma Aldrich, Germany). All solutions (perfusion, digestion, TB-A, TB-B, calibration solution I and II) were prepared as stock solutions by using distilled water. After the $\mathrm{pH}$ was titrated, these stock solutions were diluted with distilled water to the appropriate concentration before use.

Mepivacaine hydrochloride (SML1444) was diluted in TB-B solution to obtain drug concentrations of 10, 20, $40,50,75$ and $100 \mu \mathrm{M}$. For intracellular $\mathrm{Ca}^{2+}$ concentration measurements, Fluo-4 AM was obtained from Molecular Probes (F14201). Stock solutions of $1 \mathrm{mM}$ Fluo-4 AM were prepared in DMSO (Hibri-Max, cat no. $\mathrm{D} 2650$,), stored at $-20^{\circ} \mathrm{C}$ and dissolved in TB-B at $10 \mu \mathrm{M}$ prior incubation. $\mathrm{NiCl}_{2}$ (451193-5G) and ORM10103 (SML0972) were freshly dissolved in TB-B at 1 $\mathrm{mM}$ and $10 \mu \mathrm{M}$ respectively.

\section{Statistical analysis}

The power analysis was performed with G*Power software ( $G *$ Power 3.1 .7 by Axel Buchner, University of Düsseldorf, Germany). Statistical analyses were performed using GraphPad Prism software, Version 7.0 for Windows (GraphPad Software, San Diego, CA, USA). 
To obtain $\mathrm{IC}_{50}$ of mepivacaine peak area (nM*s) log dose vs response analysis was used. Data were fitted by logistic regression and the $\mathrm{IC}_{50}$ value was calculated. As the biophysical parameter values of $\mathrm{Ca}^{2+}$ transient analyses did not show a normal distribution (Kolmogorov-Smirnov test), a two-tail nonparametric test (Mann-Whitney $\mathrm{U})$ was used to compare the parameters between control and mepivacaine treated cardiomyocytes in the second protocol of the study. Since it was averaged 7 out of 10 $\mathrm{Ca}^{2+}$ transients from each recorded cardiomyocyte, the data are presented as the mean and standard error. The comparison of baseline between control, NCX blockers $\mathrm{NiCl}_{2} 1 \mathrm{mM}$, ORM-10103 $10 \mu \mathrm{M}$ and the combination of mepivacaine $50 \mu \mathrm{M}$ and NCX blockers were performed using ANOVA one-way and Dunnett's post-doc multiple comparison test. The data is presented as mean \pm SEM and the differences were considered statistically significant at $p<0.05$.

\section{Results}

To determine the $\mathrm{IC}_{50}$, the response as the biophysical parameter Peak Area $\left(\mathrm{nM}^{*} \mathrm{~s}\right)$ obtained from the $\mathrm{Ca}^{2+}$ transients to log-dose concentrations of mepivacaine 0 , 10, 20, 40, 50, 75 and $100 \mu \mathrm{M}$ (Fig. 1a) was analyzed (Fig. 1b). The estimated $\mathrm{IC}_{50}$ value for mepivacaine was $50.85 \pm 6.79 \mu \mathrm{M}$. Therefore, and for the next protocol, the concentration of mepivacaine used was $50 \mu \mathrm{M}$ and referred as mepivacaine alone.

The incubation of cardiomyocytes with $50 \mu \mathrm{M}\left(\mathrm{IC}_{50}\right)$ of mepivacaine induced a drastic reduction of the $\mathrm{Ca}^{2+}$ transient compared to control (Fig. 2a). This reduction was confirmed by the no-parametric statistical analyses showing significant inhibition in several biophysical parameters of $\mathrm{Ca}^{2+}$ transients. Mepivacaine, significantly reduced the parameters that describe the general aspects of the $\mathrm{Ca}^{2+}$ transients, such as baseline (control: $356.8 \pm 42.12 \mathrm{nM} ; n=42$ cells vs mepivacaine: $132.2 \pm 14.55 \mathrm{nM} ; n=29$ cells; $p<0.05$; Fig. 2b), peak area (control: $401.7 \pm 63.09 \mathrm{nM}$ *s vs mepivacaine: $72.14 \pm 10.46 \mathrm{nM}^{*}$; $p<0.05$; Fig. $2 \mathrm{c}$ ) and $\mathrm{D}_{50}$ (control: $457.1 \pm 47.16 \mathrm{~ms}$ vs mepivacaine: $284.5 \pm 22.71 \mathrm{~ms} ; p<0.05$; Fig. 2d). However, the total duration of the $\mathrm{Ca}^{2+}$ transient was not significantly reduced by mepivacaine (control:
$1511 \pm 111.6 \mathrm{~ms}$ vs mepivacaine: $1181 \pm 76.46 \mathrm{~ms} ; p>0.05$; Fig. 2e). Additionally, the biophysical parameters which evaluate the $\mathrm{Ca}^{2+}$ release showed that peak (control: $528.6 \pm 73.61 \mathrm{nM}$ vs mepivacaine: $130.9 \pm 15.63 \mathrm{nM} ; \mathrm{p}<$ 0.05 ; Fig. 3a), slope (control: $7699 \pm 1110 \mathrm{nM} / \mathrm{s}$ vs mepivacaine: $1686 \pm 226.6 \mathrm{nM} / \mathrm{s} ; \mathrm{p}<0.05$; Fig. $3 \mathrm{~b}$ ) and time to peak (control: $107.9 \pm 8.967 \mathrm{~ms}$ vs mepivacaine: $83.61 \pm 7.650 \mathrm{~ms}$; $\mathrm{p}<0.05$; Fig. 3c) were significantly reduced under mepivacaine influence. Regarding the re-uptake biophysical parameters, mepivacaine had no significant effect such as tau (control: $0.7540 \pm 0.05374$ vs mepivacaine: $0.6838 \pm 0.05698$; $p>0.05$ ), and time to uptake (control: $1405 \pm 112.1 \mathrm{~ms}$ vs mepivacaine: $1079 \pm 77.92 \mathrm{~ms}$; $\mathrm{p}>0.05$ ).

To test the hypothesis that NCX would contribute to the change of $\mathrm{Ca}^{2+}$ baseline in presence of mepivacaine, independent set of isolated cardiomyocytes from 3 mice were used to test two different NCX blockers alone and in combination with mepivacaine: $\mathrm{NiCl}_{2}(1 \mathrm{mM})$ and ORM-10103 $(10 \mu \mathrm{M})$. In comparison to control solution (control $313.7 \pm 21.45 \mathrm{nM;} n=27$ cells), neither $\mathrm{NiCl}_{2}$ $(252.5 \pm 33.87 \mathrm{nM}, \quad n=31$ cells) nor ORM-10103 (361.5 $\pm 30.06 ; n=24$ cells) alone did not alter the baseline signal. Similar result was obtained with the peak area parameter, where $\mathrm{NiCl}_{2}\left(372 \pm 78.56 \mathrm{nM}^{*} \mathrm{~s}\right)$ and ORM-10103 (474.3 $\left.\pm 57.67 \mathrm{nM}^{*} \mathrm{~s}\right)$ were not statistically different from control solution $\left(415.4 \pm 36.13 \mathrm{nM}^{*} \mathrm{~s}\right)$. The recorded of isolated cardiomyocytes for each combination of $\mathrm{NiCl}_{2}$ or ORM-10103 with mepivacaine induced two major responses (Fig. 4). Most of the isolated cardiomyocytes that still had a normal phenotype under the combination of NCX blocker and mepivacaine showed an intense fluorescent signal and did not responded to electrical stimulation, indicating an increase in the cytosolic $\mathrm{Ca}^{2+}$ concentration and thus suggesting cell death. Few cardiomyocytes responded to initial electrical stimulation ( $n=10$ cells each combination), but entered in arrhythmia or increased the fluorescent signal with after few stimulations (Fig. 4a and b). In comparison to control, there was a significant increase in the baseline $\mathrm{Ca}^{2+}$ concentration in cardiomyocytes recorded with the combination of mepivacaine and $\mathrm{NiCl}_{2}$ (Fig. 4a: $508.1 \pm$ $74.68 \mathrm{nM} ; \mathrm{F}_{6,32}=0.2067 ; p<0.01$ ) or mepivacaine with

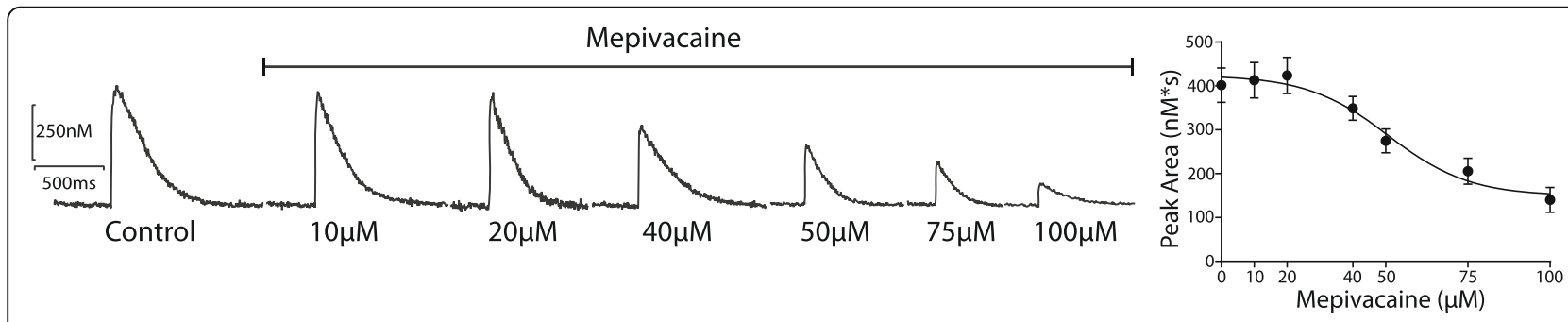

Fig. 1 Representative $\mathrm{Ca}^{2+}$ transients' traces to the dose-response effect of mepivacaine at 0, 10, 20, 40, 50, 75 and $100 \mu \mathrm{M}$ (a). Log dose-response analysis of the peak area $\left(\mathrm{nM}^{*} \mathrm{~s}\right)$ parameter was analyzed, obtaining the $\mathrm{IC}_{50}$ value of $50.85 \pm 6.79 \mu \mathrm{M}$ 


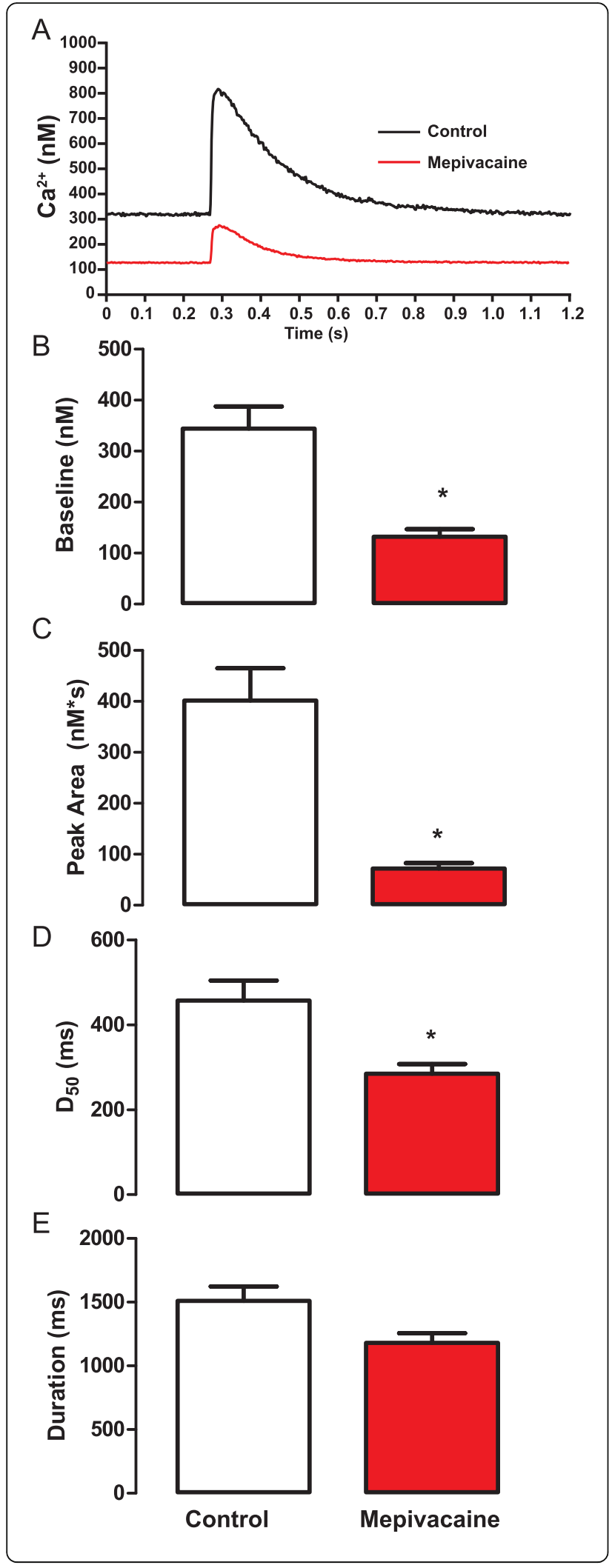

Fig. 2 Representative $\mathrm{Ca}^{2+}$ transients trace demonstrating the inhibitory effect of mepivacaine at half maximal inhibitory concentration $\left(\mathrm{IC}_{50}\right)$ on in isolated mouse ventricular cardiomyocytes (a). Summarized data for the effect of mepivacaine $\left(\mathrm{IC}_{50}\right)$ on biophysical parameters describing the general aspects of the $\mathrm{Ca}^{2+}$ transients: baseline (b) peak area (c), Duration at $50 \%$ of the maximum $\mathrm{D}_{50}(\mathbf{d})$ and duration (e). Results are expressed as mean \pm SEM. Symbol $(*)$ indicates significant change from control $(p<0.05)$. $n=42$ cells for control and $n=29$ cells for mepivacaine group

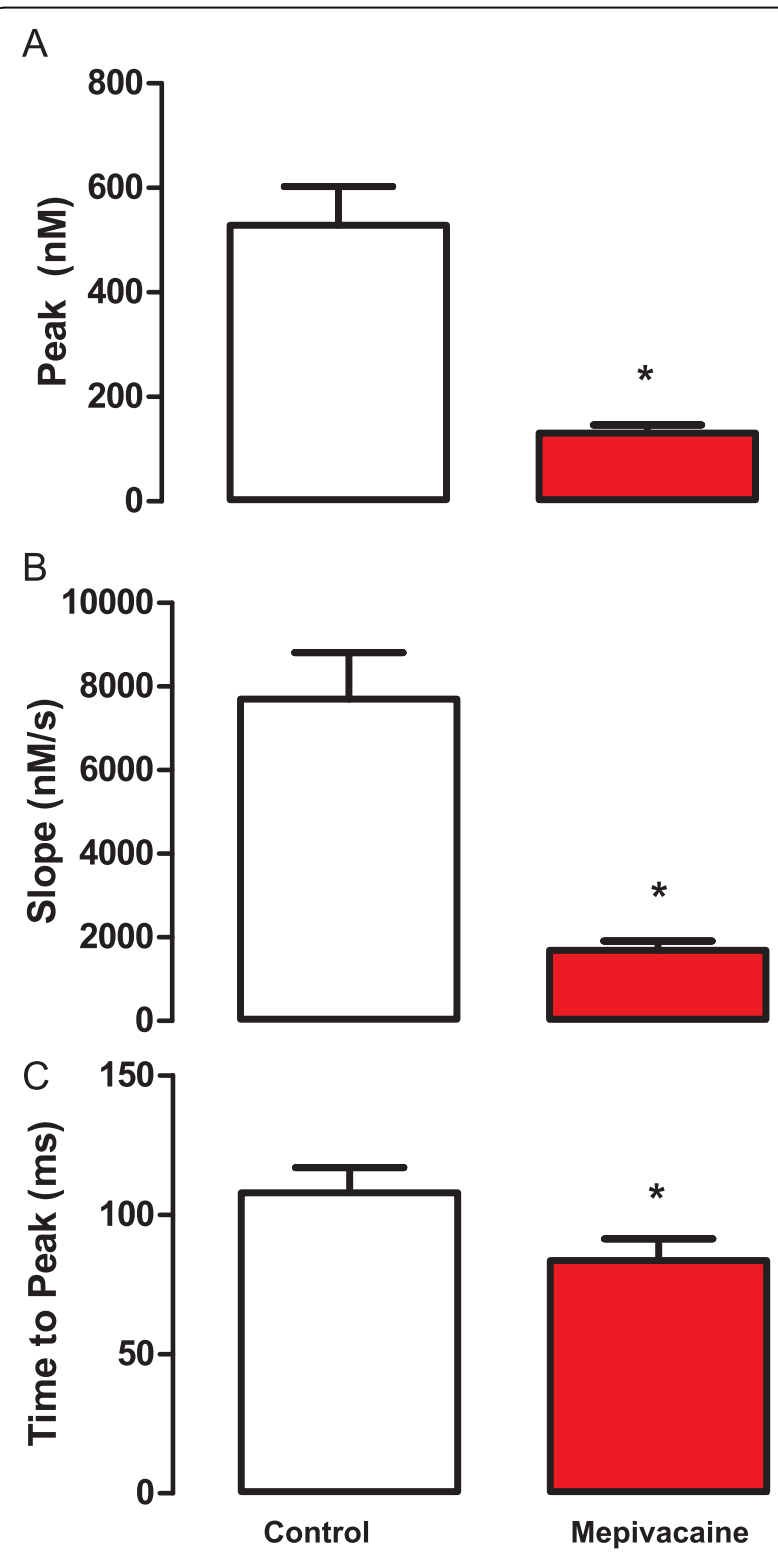

Fig. 3 Summarized data for the effect of mepivacaine at $I C_{50}$ on $\mathrm{Ca}^{2+}$ release's biophysical parameters obtained from $\mathrm{Ca}^{2+}$ transients: peak (a), slope (b) and time to peak (c). Results are expressed as mean \pm SEM. Symbol $(*)$ indicates significant change from control $(p<0.05)$. $n=42$ cells for control and $n=29$ cells for mepivacaine group 


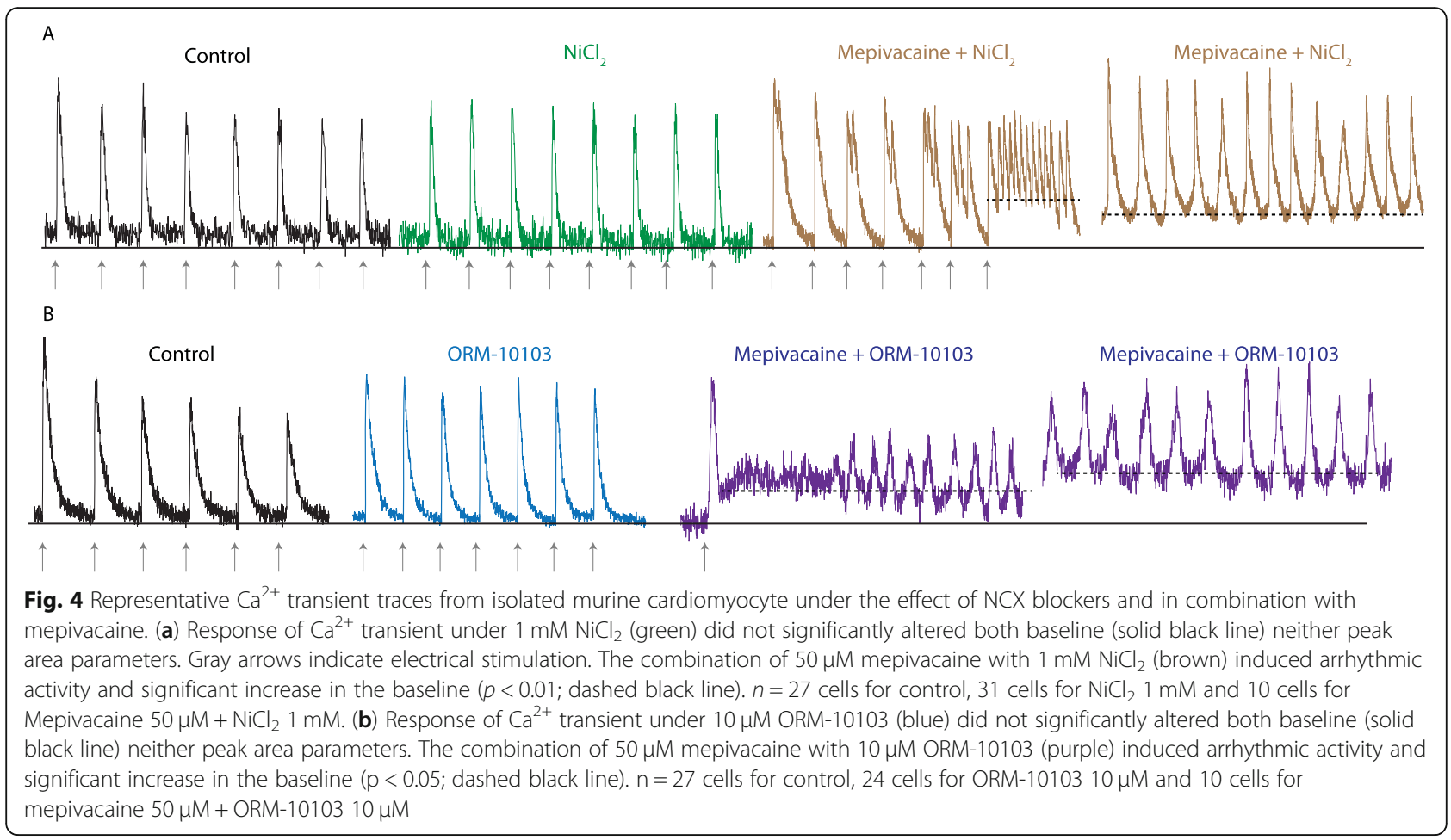

ORM-10103 (Fig. 4b: $450.8 \pm 72.44 \mathrm{nM;} \quad \mathrm{F}_{6,32}=0.2067$; $p<0.05)$.

\section{Discussion}

Using a combination of $\mathrm{Ca}^{2+}$ transient data recording technique and data analysis based on biophysical parameters we described a new possible role of mepivacaine observed in murine isolated cardiomyocyte's $\mathrm{Ca}^{2+}$ homeostasis. This combination provides fine details of mepivacaine's action, showing new effect on $\mathrm{Ca}^{2+}$ release and uptake during EC-coupling. Mepivacaine's effect was first established finding the $\mathrm{IC}_{50}$ value to reduce the peak area of the recorded $\mathrm{Ca}^{2+}$ transients calculated as $50.85 \pm 6.79 \mu \mathrm{M}$. To assess the clinical relevance of the present study, our findings need to be interpreted in correlation to experimental conditions, which differ from physiological conditions in vivo. Typically, the therapeutic plasma levels found of mepivacaine range from 4 to $6 \mu \mathrm{g}$ per $\mathrm{ml}$ [9]. However, thresholds for onset of local anesthetics toxicity are subject to a wide inter-individual range $[18,19]$. Toxicity has been reported with a peak mepivacaine plasma concentration of $5.1 \mu \mathrm{g}$ per $\mathrm{ml}$ [20], but the critical threshold dose seems to be a concentration of $6,27 \mu \mathrm{g}$ mepivacaine-hydrochloride per $\mathrm{ml}$ blood plasma, which leads to a concentration of mepivacaine of $25,48 \mu \mathrm{M}[21,22]$. Moreover, all anesthetics bind to plasma proteins, which decrease the effective circulating concentration of these anesthetics. Therefore, the actual free plasma concentration of anesthetic available to bind to tissues will be a fraction of the total plasma concentration [23, 24]. Despite the large difference between the clinical anesthetic dosage and the concentration used in our study, we showed in isolated murine cardiomyocytes a new possible role of mepivacaine affecting directly ECcoupling, by reducing $\mathrm{Ca}^{2+}$ release. It is also relevant to note that the same concentration of mepivacaine was used in Park \& Suh [9] and in our results, suggesting that in rodents mepivacaine might have a small potency as described for humans, needing a supra-clinical dosage in order to observe any effect. For instance, in mouse neuroblastoma $\mathrm{N} 2 \mathrm{~A}$ an $\mathrm{IC}_{50}$ of $74.2 \mu \mathrm{M}$ mepivacaine showed higher concentration- and state-dependent effect on tonic blockade of voltage-gated $\mathrm{I}_{\mathrm{Na}}$ at holding potentials of $-100 \mathrm{mV}$ [25]. Other reports show that varying mepivacaine's concentration from $21 \mu \mathrm{M}$ to $81 \mu \mathrm{M}$ is used for antinociceptive effects by sciatic nerve blockade in mice [26], $40 \mu \mathrm{M}$ mepivacaine to induce significant reduction on $\mathrm{I}_{\mathrm{Na}}$ in isolated murine cardiomyocytes [7] and a wide range from $2 \mathrm{mM}$ to $32 \mathrm{mM}$ mepivacaine to ameliorate HIV sensory neuropathy in rats [27]. Therefore, the concentration of mepivacaine used here goes in concordance with previous results using mice and rats, supporting the evidences of lower mepivacaine potency in rodents.

Using the $\mathrm{IC}_{50}$ of $50 \mu \mathrm{M}$ mepivacaine to analyze the biophysical parameters, it was observed that mepivacaine was able to reduce the $\mathrm{Ca}^{2+}$ release, without major effect on $\mathrm{Ca}^{2+}$ uptake. It is well established that mepivacaine 
has negative chronotropic and inotropic effects, as well ventricular arrhythmias and decrease of QTc- interval $[5,6,28]$. In dogs, there is also a significant increase of T-wave's area-under-curve, lengthening of QTU interval and enhancing slow wave as interval of U-wave following T-wave [28]. These alterations on mepivacainemediated cardiac performance is explained in the ventricular cardiomyocyte to mepivacaine-induced $\mathrm{I}_{\mathrm{Na}}$ reduction effect [7], which, as seen with lidocaine, reduces intracellular $\mathrm{Na}^{+}$concentration, reducing $\mathrm{Na}$ $\mathrm{Ca}$ exchanger reverse activity (inward $\mathrm{Ca}^{2+}$ ) and thus the reducing intracellular $\mathrm{Ca}^{2+}$ concentration and consequently myocardial contractility [29]. It is well established that mepivacaine becomes active after cytosolic protonation, allowing it to bind to the alpha unit of the voltage-gated $\mathrm{Na}^{+}$channel. This reverse binding and thus blocking process occurs only from the cytosolic side when the $\mathrm{Na}^{+}$channel is open resulting in a reduction of $\left[\mathrm{Na}^{+}\right]_{\mathrm{i}}[30-34]$. It is wellestablished in physiological and pathophysiological conditions that $\mathrm{Na}^{+}-\mathrm{Ca}^{2+}$ exchanger has its most favorable thermodynamic activity occurs during diastole, extruding $\mathrm{Ca}^{2+}$ [35-38]. Under physiological conditions, NCX operates in the forward mode, moving $\mathrm{Na}^{+}$to cytosol and $\mathrm{Ca}^{2+}$ to extracellular milieu, which results in a reduced intracellular diastolic $\mathrm{Ca}^{2+}$ levels [39]. This would be the case set by mepivacaine, where the reduced $\left[\mathrm{Na}^{+}\right]_{\mathrm{i}}$ activates NCX forward mode in order to avoid arrhythmias, resulting in a reduced sarcoplasmic reticulum $\mathrm{Ca}^{2+}$ after few $\mathrm{Ca}^{2+}$ transients. In order to test this hypothesis, we combined the use of mepivacaine with either two NCX blockers: $\mathrm{NiCl}_{2}$ and ORM-10103 both reduce the NCX forward and reverse currents [40]. The alone effect of either $\mathrm{NiCl}_{2}$ or ORM-10103 did not produce a significant change in the baseline, neither in the peak area of the recorded $\mathrm{Ca}^{2+}$ transients, supporting others and our previous published data [12, 40]. The combination of mepivacaine with either $\mathrm{NiCl}_{2}$ or ORM10103 produced two results: few cardiomyocytes responded with few electrical stimulation, followed by consecutive $\mathrm{Ca}^{2+}$ transients without electrical stimulation, similar to arrhythmic activity. However, most of the cardiomyocytes that received both drugs and still presented the characteristic isolated cardiomyocyte phenotype did not respond to the electrical stimulation, showing in some of them an intense background fluorescence signal. These results suggested that blocking both $\mathrm{Na}^{+}$and $\mathrm{Ca}^{2+}$ homeostasis simultaneously would lead to arrhythmogenic activity and probably leading to cell death. Therefore, in combination with our baseline results, these data support the suggested hypothesis, where mepivacaine's action via blocking $\mathrm{Na}^{+}$channels significantly reduced intracellular $\mathrm{Ca}^{2+}$ concentration during diastole by enhancing the NCX reverse mode activity. However, this result must be carefully taken due to the limitation of the technique.

The negative inotropic effects of mepivacaine in ventricular papillary muscles have been previously reported [8, 9]. Park and Suh [9] studied the effects of $50 \mu \mathrm{M}$ mepivacaine in isolated guinea pig and rat right ventricular papillary muscles, resulting in approximately $40 \%$ depression of peak force, concluding that the direct myocardial depressant effect of mepivacaine is likely to be caused by reduced $\mathrm{Ca}^{2+}$ release from the sarcoplasmic reticulum. David and colleagues [8] compared the inotropic and lusitropic effects of lidocaine and mepivacaine on rat left ventricular papillary muscles, showing that mepivacaine only induced a negative inotropic effect when added as a bolus for the highest concentration (1 $\mathrm{mM}$ ) and this effect was significantly more pronounced with lidocaine than with mepivacaine. Moreover, a negative lusitropic effect was observed during isotonic contractions only for mepivacaine suggesting a reduction of $\mathrm{Ca}^{2+}$ in the sarcoplasmic reticulum. However, the fact that the post-rest potentiation was not significantly modified by mepivacaine or by lidocaine, indicating that $\mathrm{Ca}^{2+}$ efflux from the sarcoplasmic reticulum was not significantly influenced. Regarding the effects of mepivacaine on $\mathrm{Ca}^{2+}$ release, the results of David and colleagues [8] were in conflict with those reported by Park and Suh [9], where the latter suggest an inhibitory effect on $\mathrm{Ca}^{2+}$ release that was not confirmed by David and colleagues. Since the potential mechanism of mepivacaine's myocardial depressant effect was not completely cleared, we investigated the consequences of mepivacaine influence in the general aspects of the $\mathrm{Ca}^{2+}$ transients, the parameters peak area, duration and $\mathrm{D}_{50}$ were analyzed. As shown in Fig. 2c and Fig. 2d, mepivacaine decreased peak area and $\mathrm{D}_{50}$ significantly. The present results suggest that the reduced $\mathrm{Ca}^{2+}$ transients could be caused by the activity of $\mathrm{Na}^{+}-\mathrm{Ca}^{2+}$ exchanger, inwarding $\mathrm{Na}^{+}$and extruding $\mathrm{Ca}^{2+}$, which would lead to reduced sarcoplasmic reticulum $\mathrm{Ca}^{2+}$ concentration; alternatively, mepivacaine would also altered kinetics of $\mathrm{Ca}^{2+}$ release and/or $\mathrm{Ca}^{2+}$ uptake in the sarcoplasmic reticulum by an unknown mechanism. The biophysical parameters analyzed related to $\mathrm{Ca}^{2+}$ release and $\mathrm{Ca}^{2+}$ uptake showed that mepivacaine significantly reduced all three parameters which evaluate the $\mathrm{Ca}^{2+}$ release: peak, slope and time to peak. All together, these parameters suggest that mepivacaine would reduce the amount of $\mathrm{Ca}^{2+}$ released into the cytosol and its rate of release and thus, the time to reach its maximum. Finally, we observed no effect of mepivacaine on cardiomyocytes' $\mathrm{Ca}^{2+}$ uptake by analyzing the parameters tau and time to uptake. However, this no effect cannot completely be excluded due to mepivacaine's major effect on the $\mathrm{Ca}^{2+}$ 
release without challenging cardiomyocytes' $\mathrm{Ca}^{2+}$ uptake mechanisms.

\section{Conclusion}

This is the first study that evaluated the direct effects of mepivacaine on $\mathrm{Ca}^{2+}$ transients in isolated, adult mouse ventricular myocytes. Our findings in isolated cardiomyocyte preparations provide evidences to explain that the negative inotropic effect of mepivacaine found previously in cardiac muscle is due to its modulating effects on $\mathrm{Ca}^{2+}$ regulation at cellular level, specifically on $\mathrm{Ca}^{2+}$ release.

\section{Abbreviations}

$D_{50}$ : Time duration at $50 \%$ of the maximum.; $d_{v} / d_{\text {tmax: }}$ Maximum slope of action potential during depolarization.; $F_{\text {max: }}$ Maximum fluorescence intensity.; $F_{\text {min: }}$ : Minimum fluorescence intensity.; $I_{50}$ : Inhibitory effect at $50 \%$ of the response.; TB-A: Transfer buffer A.; TB-B: Transfer buffer B.

\section{Acknowledgement}

We would like to thank Dr. Ulrike Zeiger for her comments on the manuscript.

\section{Authors' contributions}

Authors MM, GA and RHAF contributed to the study design and planning, drafting and revising the paper. Authors MM and GA carried out the study conduct, and author MM performed the data analysis. All authors read and approved the final manuscript.

\section{Funding}

Funding agencies have no role or decision in the design of the study and collection, analysis, and interpretation of data and in writing the manuscript. The scientific work was partially financed by German Federal Ministry of Education and Science (BMBF; MM, Grant number 031A552). We acknowledge financial support by Deutsche Forschungsgemeinschaft within the funding program Open Access Publishing, by the Baden-Württemberg Ministry of Science, Research and the Arts and by Ruprecht-Karls-Universität Heidelberg for supporting publication costs.

\section{Availability of data and materials}

The data produced in this manuscript was deposited in public archive under DOl https://doi.org/10.6084/m9.figshare.7713074.v1.

\section{Ethics approval and consent to participate}

All animal experiments were performed in accordance with the governmental guidelines of the state Baden Württemberg, including the German law on animal experimentation, and were approved by the ethics committee of Heidelberg University Interfaculty Biomedical Research Facility (T84/14).

\section{Consent for publication}

Not Applicable.

\section{Competing interests}

The authors declare that they have no competing interest.

Received: 10 July 2019 Accepted: 30 December 2019

Published online: 08 January 2020

\section{References}

1. Butterworth JF. Models and mechanisms of local anesthetic cardiac toxicity: a review. Reg Anesth Pain Med. 2010;35(2):167-76.

2. Groban L, Deal DD, Vernon JC, James RL, Butterworth J. Does local anesthetic stereoselectivity or structure predict myocardial depression in anesthetized canines? Reg Anesth Pain Med. 2002;27(5):460-8.

3. Mather LE, Chang DH. Cardiotoxicity with modern local anaesthetics: is there a safer choice? Drugs. 2001;61(3):333-42.

4. Tagariello V, Caporuscio A, De Tommaso O. Mepivacaine: update on an evergreen local anaesthetic. Minerva Anestesiol. 2001;67(9 Suppl 1):5-8.
5. Harvey M, Cave G, Chanwai G, Nicholson T. Successful resuscitation from bupivacaine-induced cardiovascular collapse with intravenous lipid emulsion following femoral nerve block in an emergency department. Emerg Med Australas. 2011;23(2):209-14.

6. Ozcan MS, Weinberg G. Update on the use of lipid emulsions in local anesthetic systemic toxicity: a focus on differential efficacy and lipid emulsion as part of advanced cardiac life support. Int Anesthesiol Clin. 2011; 49(4):91-103.

7. Wagner M, Zausig YA, Ruf S, Rudakova E, Gruber M, Graf BM, et al. Lipid rescue reverses the bupivacaine-induced block of the fast $\mathrm{Na}+$ current $(\mathrm{INa})$ in cardiomyocytes of the rat left ventricle. Anesthesiol. 2014;120(3):724-36.

8. David JS, Amour J, Duracher C, Ferretti C, Precloux P, Petit P, et al. Comparison of the effects of mepivacaine and lidocaine on rat myocardium. Eur J Anaesthesiol. 2007;24(2):190-7.

9. Park WK, Suh CK. Mechanical and electrophysiological effects of mepivacaine on direct myocardial depression in vitro. Br J Anaesth. 1998; 81(2):244-6.

10. Scheid LM, Mosqueira M, Hein S, Kossack M, Juergensen L, Mueller M, et al. Essential light chain S195 phosphorylation is required for cardiac adaptation under physical stress. Cardiovasc Res 2016;111(1):44-55.

11. Xiyuan Z, Fink RHA, Mosqueira M. NO-sGC pathway modulates Ca (2+) release and muscle contraction in Zebrafish skeletal muscle. Front Physiol. 2017;8:607.

12. Yampolsky P, Koenen M, Mosqueira M, Geschwill P, Nauck S, Witzenberger $\mathrm{M}$, et al. Augmentation of myocardial if dysregulates calcium homeostasis and causes adverse cardiac remodeling. Nat Commun. 2019;10(1):3295.

13. Liao R, Jain M. Isolation, culture, and functional analysis of adult mouse cardiomyocytes. Methods Mol Med. 2007;139:251-62.

14. Bers DM. Ca influx and sarcoplasmic reticulum Ca release in cardiac muscle activation during postrest recovery. Am J P hys. 1985;248(3 Pt 2):H366-81.

15. Capogrossi MC, Kort AA, Spurgeon HA, Lakatta EG. Single adult rabbit and rat cardiac myocytes retain the $\mathrm{Ca} 2+-$ and species-dependent systolic and diastolic contractile properties of intact muscle. J Gen Physiol. 1986;88(5): 589-613.

16. WH DB, Boyett MR, Spurgeon HA, Talo A, Stern MD, Lakatta EG. The cytosolic calcium transient modulates the action potential of rat ventricular myocytes. J Physiol. 1991;436:347-69.

17. Grynkiewicz G, Poenie M, Tsien RY. A new generation of Ca2+ indicators with greatly improved fluorescence properties. J Biol Chem. 1985;260(6): $3440-50$.

18. Niemi TT, Neuvonen PJ, Rosenberg PH. Comparison of ropivacaine $2 \mathrm{mg}$ $\mathrm{ml}(-1)$ and prilocaine $5 \mathrm{mg} \mathrm{ml}(-1)$ for i.v. regional anaesthesia in outpatient surgery. Br J Anaesth. 2006;96(5):640-4.

19. Yamamoto K, Nomura T, Shibata K, Ohmura S. Failed axillary brachial plexus block techniques result in high plasma concentrations of mepivacaine. Reg Anesth. 1997:22(6):557-61.

20. Tanoubi I, Vialles N, Cuvillon P, Ripart J. Systemic toxicity with mepivacaine following axillary block in a patient with terminal kidney failure. Ann $\mathrm{Fr}$ Anesth Reanim. 2006;25(1):33-5.

21. Dillane D, Finucane BT. Local anesthetic systemic toxicity. Can J Anaesth. 2010;57(4):368-80

22. Morishima HO, Daniel SS, Finster M, Poppers PJ, James LS. Transmission of mepivacaine hydrochloride (carbocaine) across the human placenta. Anesthesiology. 1966;27(2):147-54

23. Tucker GT, Boyes RN, Bridenbaugh PO, Moore DC. Binding of anilide-type local anesthetics in human plasma. I. Relationships between binding, physicochemical properties, and anesthetic activity. Anesthesiol. 1970;33(3): 287-303.

24. Tucker GT, Moore DC, Bridenbaugh PO, Bridenbaugh LD, Thompson GE. Systemic absorption of mepivacaine in commonly used regional block procedures. Anesthesiol. 1972;37(3):277-87.

25. Leung YM, Chu CC, Kuo CS, Chen YW, Wang JJ. Nisoxetine blocks sodium currents and elicits spinal anesthesia in rats. Pharmacol Rep. 2013;65(2):350-7.

26. de Araujo DR, Cereda CM, Brunetto GB, Pinto LM, Santana MH, de Paula E. Encapsulation of mepivacaine prolongs the analgesia provided by sciatic nerve blockade in mice. Can J Anaesth. 2004;51(6):566-72.

27. Sagen J, Castellanos DA, Hama AT. Antinociceptive effects of topical mepivacaine in a rat model of HIV-associated peripheral neuropathic pain. J Pain Res. 2016;9:361-71.

28. Kasten GW. Amide local anesthetic alterations of effective refractory period temporal dispersion: relationship to ventricular arrhythmias. Anesthesiol. 1986;65(1):61-6. 
29. Sheu SS. Cytosolic sodium concentration regulates contractility of cardiac muscle. Basic Res Cardiol. 1989;84(Suppl 1):35-45.

30. Harmatz A. Local anesthetics: uses and toxicities. Surg Clin North Am. 2009; 89(3):587-98.

31. Kress GJ, Mennerick S. Action potential initiation and propagation: upstream influences on neurotransmission. Neurosci. 2009;158(1):211-22.

32. Lovinger DM. Communication networks in the brain: neurons, receptors, neurotransmitters, and alcohol. Alcohol Res Health. 2008;31(3):196-214.

33. Platkiewicz J, Brette R. A threshold equation for action potential initiation. PLoS Comput Biol. 2010;6(7):e1000850.

34. Skidmore RA, Patterson JD, Tomsick RS. Local anesthetics. Dermatol Surg. 1996;22(6):511-22 quiz 23-4.

35. Bridge JH, Smolley JR, Spitzer KW. The relationship between charge movements associated with ICa and INa-Ca in cardiac myocytes. Sci. 1990; 248(4953):376-8.

36. Luo CH, Rudy Y. A dynamic model of the cardiac ventricular action potential. I. Simulations of ionic currents and concentration changes. Circ Res. 1994;74(6):1071-96.

37. Diaz ME, Graham HK, Trafford AW. Enhanced sarcolemmal Ca2+ efflux reduces sarcoplasmic reticulum $\mathrm{Ca} 2+$ content and systolic $\mathrm{Ca} 2+$ in cardiac hypertrophy. Cardiovasc Res. 2004;62(3):538-47.

38. Eisner DA, Diaz ME, Li Y, O'Neill SC, Trafford AW. Stability and instability of regulation of intracellular calcium. Exp Physiol. 2005;90(1):3-12.

39. Pieske B, Houser SR. [Na+]i handling in the failing human heart. Cardiovasc Res. 2003;57(4):874-86

40. Nagy N, Kormos A, Kohajda Z, Szebeni A, Szepesi J, Pollesello P, et al. Selective $\mathrm{Na}(+) / \mathrm{Ca}(2+)$ exchanger inhibition prevents $\mathrm{Ca}(2+)$ overloadinduced triggered arrhythmias. Br J Pharmacol. 2014;171(24):5665-81.

\section{Publisher's Note}

Springer Nature remains neutral with regard to jurisdictional claims in published maps and institutional affiliations.

Ready to submit your research? Choose BMC and benefit from:

- fast, convenient online submission

- thorough peer review by experienced researchers in your field

- rapid publication on acceptance

- support for research data, including large and complex data types

- gold Open Access which fosters wider collaboration and increased citations

- maximum visibility for your research: over $100 \mathrm{M}$ website views per year

At $\mathrm{BMC}$, research is always in progress.

Learn more biomedcentral.com/submissions 